\title{
High-Gain Annular Ring With Meander Slots Antenna Array for RFID APPLICATIONS
}

\author{
Basma M. Yousef ${ }^{1}$, Zeeshan Yousuf ${ }^{2}$, Allam M. Ameen ${ }^{3}$, Ayman Elboushi $^{3}$ \\ ${ }^{1}$ Delta Higher Institute for Engineering and Technology, Mansoura, Egypt, basmamyousef@gmail.com \\ ${ }^{2}$ Centre for Wireless Communications, University of Oulu, Oulu, Finland \\ ${ }^{3}$ Electronics Research Institute, Cairo, Egypt, a_m_fekry@eri.sci.eg, allamameen@eri.sci.eg
}

\begin{abstract}
In this paper, a high-gain annular ring with meander slots antenna array is presented. The proposed design is realized on two different substrate materials separated by a foam layer of $7.5 \mathrm{~mm}$ to enhance the operating bandwidth. The antenna is designed to operated as UHF-RFID reading antenna over center frequency of $915 \mathrm{MHz}$ with operating bandwidth of $49.25 \mathrm{MHz}$ (around 5.38\%). The overall antenna optimized dimensions are 240x240x11.56 $\mathrm{mm}^{3}$. An overall total realized gain of $12.5 \mathrm{dBi}$ is achieved at the intended center frequency. The proposed antenna exhibits stable radiation capabilities over the operating band. Good agreement is obtained between both CSTMWS, and HFSS simulators.
\end{abstract}

Keywords: UHF-RFID, Meander slots, annular ring antenna, array antenna.

\section{INTRODUCTION}

RFID "Radio Frequency Identification" is the technology that using RF signals to provide wireless identification and tracking capabilities. RFID systems consist of four principle items: reader, tag, antenna and host computer [1]. Antennas are the main link component from the tag to the reader. RFID has been used in many applications such as smart labels, preventing theft of automobiles, banking, animal tracking, managing traffic, automating park, ticketing, etc. [2]. RFID systems have different frequency bands for example low frequency band from $125 \mathrm{KHz}$ to $134.5 \mathrm{KHz}$, and the high frequency band works at central frequency about $13.56 \mathrm{MHz}$. The band from $433 \mathrm{MHz}$ to $960 \mathrm{MHz}$ has been used for ultra-high frequency (UHF-RFID) signal transmission [3]. The microwave range frequencies (2400-2485 MHz and 5725-5875 MHz) are increasable used recently, so RFID antennas become more complicated. Readers RFID antennas must satisfy some requirements such as good impedance matching, high gain, low cost, ease of fabrication, and low profile. A low profile, dual-band, circular array of four Inverted-F meandered monopoles polarized portable antenna for RFID reader is presented in [4]. Slits on the ground plane and slots in the patch antenna are applied on a simple circular patch to achieve circular polarization at dual frequencies [5-8]. Array techniques are also used to achieve a switchable near field and far field UHF-RFID antenna [9-10]. A compact circularly polarized antenna with a cross slot in the radiation patch is presented in [11]. Overall antenna gain is enhanced by applying complementary split ring resonator on a compact UHF RFID reader antenna is discussed in [12].

In this paper, a novel design of UHF-RFID reader antenna structure with apparent enhancement in the operating bandwidth and gain is proposed. The designed antenna has a high gain by using parasitic radiator elements printed on a second substrate on the upper layer and a widely bandwidth by using a foam layer in between the two substrate. This paper is organized as follows: Section II describes the designed main element radiator structure and the radiation mechanism. The complete antenna structure is presented in Section III. The results of optimization and a parametric study are introduced in section IV. Finally, the return loss and radiation pattern results are presented in section V. The results of the proposed antenna in RFID system are simulated using CSTMWS studio and verified by HFSS software. Good agreement is achieved between two simulation results.

\section{MAIN Element RADIATOR}

A simple annular ring microstrip patch (AR-MSP) antenna is designed to operate at a central frequency 915 $\mathrm{MHz}$ for UHF-RFID applications. The patch antenna is printed on a grounded substrate of Rogers TMM4 with relative permittivity $\varepsilon_{r}=4.5, \tan \delta=0.002$ and thickness $h_{1}=3.81 \mathrm{~mm}$. The outer and inner radii of the annularring radiator are $R_{1 \text { out }}=3.6 \mathrm{~cm}$ and $R_{1 \text { in }}=1.8 \mathrm{~cm}$, respectively as shown in Fig. 1 (a). The overall size of the main radiator element is $\left(130 \times 130 \times 3.81 \mathrm{~mm}^{3}\right)$. A coaxial probe feed is used to excite the designed AR-MSP antenna. An optimization process for the feed position $\left(x_{f}, y_{f}\right)$ is introduced to select the 50-ohm matching point. An indirect coupling feeding radiation is carried out between the main annular ring patch and the meander slots 


\section{$2021,3^{\text {th }}$ NATIONAL RADIO SCIENCE CONFERENCE \\ (NRSC 2021), July 27-29, 2021}

Mansoura University, Mansoura, Egypt

stacked patch printed on the top substrate through the foam layer. The middle layer between the two substrates is chosen to be a foam with a thickness of $h_{2}=7.5 \mathrm{~mm}$ and $\varepsilon_{r}=1.01$ to enhance the overall antenna bandwidth.

The parasitic meander slots stacked patch is used to achieve more enhancement of the antenna bandwidth, impedance matching, and total realized gain of the antenna. It is placed on the second substrate $\left(s u b_{2}\right)$ of Roger TMM10 with $\varepsilon_{r}=9.2, \tan \delta=0.0022$ and thickness $h_{3}=0.25 \mathrm{~mm}$. This parasitic patch consists of an annular ring patch with eight meander slots is shown in Fig. 1 (b). The slots increase the current path to reduce the overall antenna size. The eight meander slots are divided to two groups and each group contains four slots. The first group is located vertically and horizontally with a dimension of $S_{L 1} \times S_{w}$ and the second group is located diagonally with angle $45^{\circ}$ with a dimension of $S_{L 2} \times S_{w}$. The main element radiator with the parasitic patch schematic is shown in Fig. 1. All the designed parameter dimensions of the main element radiator are summarized in Table1. The return loss of the main radiator with parasitic mender slots stacked patch is shown in Fig. 2. The bandwidth of the main element radiator is $8 \mathrm{MHz}$ at $-10 \mathrm{~dB}$. The proposed design achieves a gain of $9.87 \mathrm{~dB}$ at a resonance frequency of $915 \mathrm{MHz}$. Fig. 3 shows the radiation pattern of the proposed main element radiator (E-plane and H-plane).

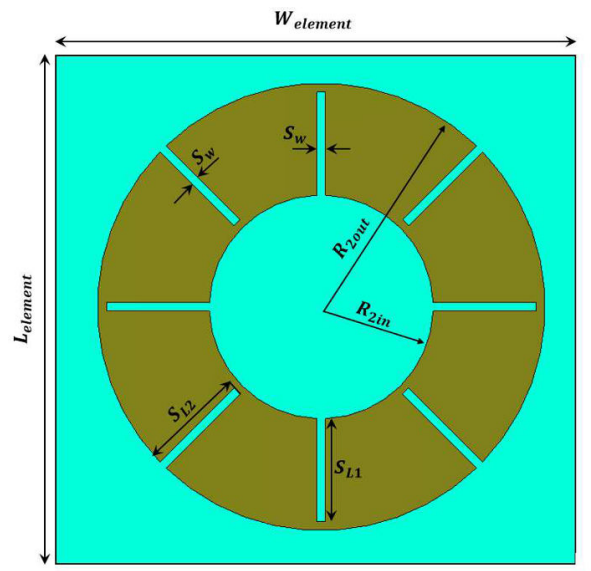

(a)

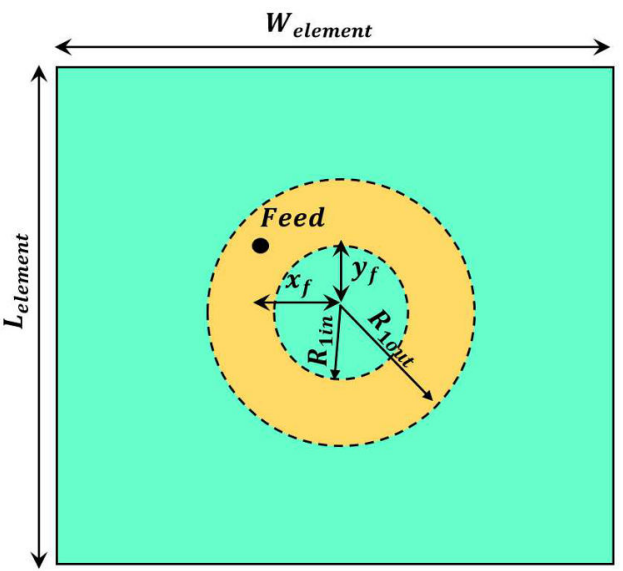

(b)

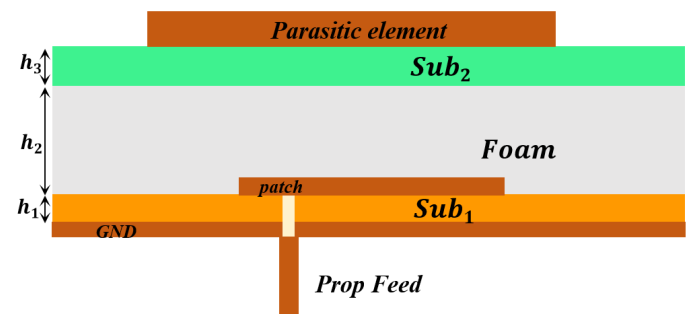

(c)

Fig. 1: (a) The annular ring microstrip radiator element (b) meander slots stacked patch and (c) Side view of the total radiator element structure

Table.1 Main element radiator dimensions

\begin{tabular}{|c|c|c|c|c|c|c|c|}
\hline Parameter & $S_{L 1}$ & $S_{L 2}$ & $S_{w}$ & $R_{1 \text { out }}$ & $R_{1 \text { in }}$ & $R_{\text {2out }}$ & $R_{2 \text { in }}$ \\
\hline Dimension (mm) & 24.5 & 25 & 0.5 & 36 & 18 & 53 & 26.5 \\
\hline Parameter & $W_{\text {element }}$ & $L_{\text {element }}$ & $x_{f}$ & $y_{f}$ & $h_{1}$ & $h_{2}$ & $h_{3}$ \\
\hline Dimension (mm) & 120 & 120 & 19.09 & 19.09 & 3.81 & 7.5 & 0.25 \\
\hline
\end{tabular}




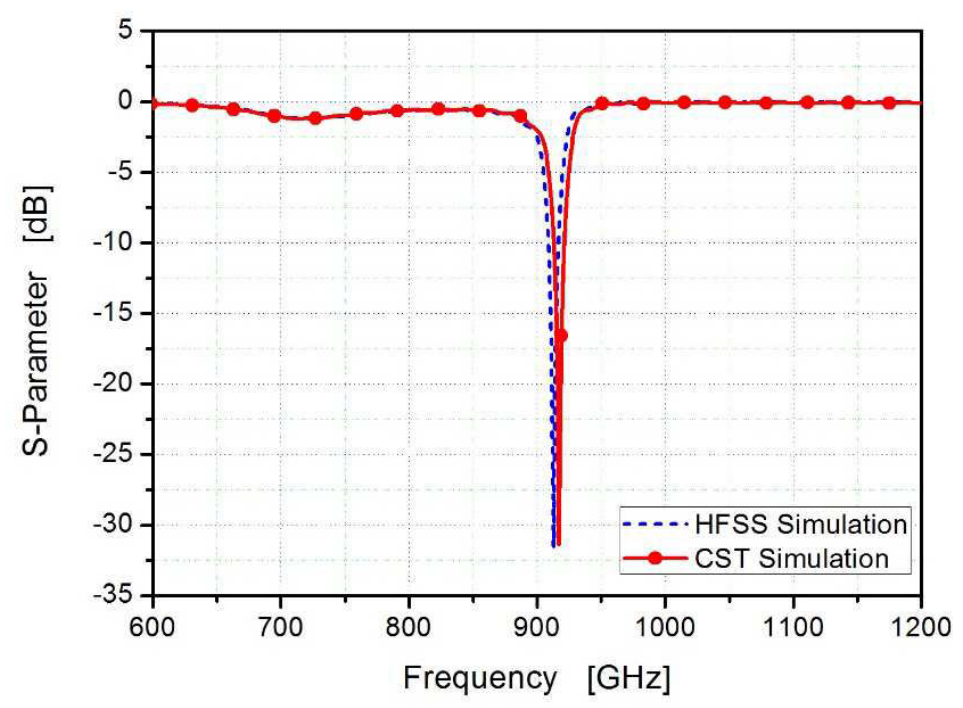

Fig. 2: The return loss of the main radiator with parasitic mender slots.

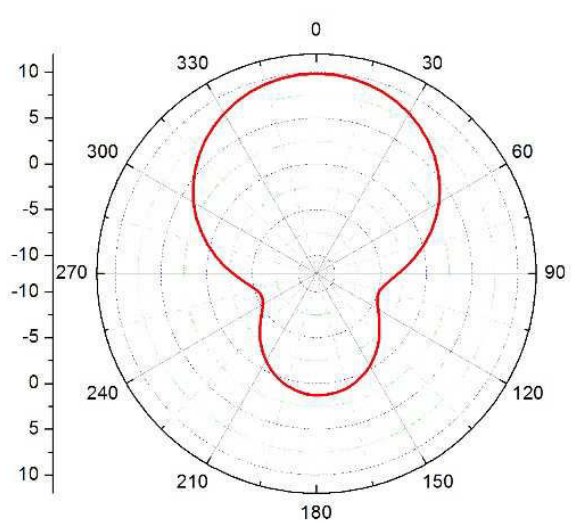

(a)

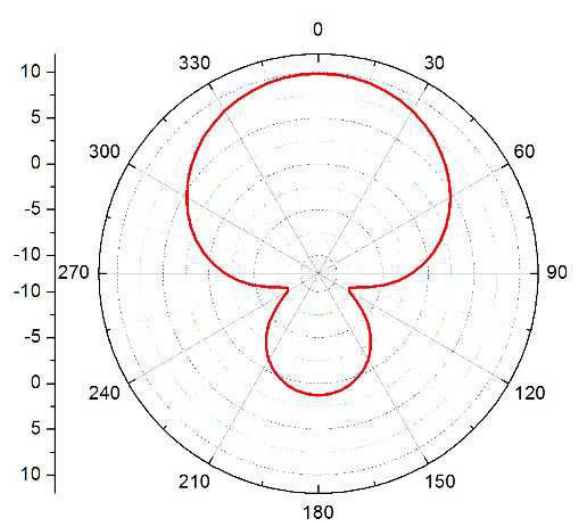

(b)

Fig. 3: The radiation pattern of the proposed main element radiator (a) E-plane, and (b) H-plane.

\section{III.COMPlete Antenna ArRay Design}

In this section, a configuration of RFID meander slots annular ring antenna array is introduced. The overall optimized size of the designed annular ring with meander slots radiators is $\left(240 \times 240 \times 11.56 \mathrm{~mm}^{2}\right)$. An $2 \times 2$ array of meander slots stacked patches is printed in the top layer of the designed antenna, as shown in Fig. 4 (a), to achieve better gain and stable radiation characteristics. The center-to-center spacing distance between the array meander slots radiator $\left(w_{1}\right)$ is equal to $118 \mathrm{~mm}$. A parametrical study is applied to adjust the separation distance between the four meander slots patches. In Fig. 4 (b), the side view of the proposed antenna is presented. The coaxial probe feed is realized on the bottom layer which optimized to determine the best matching point location for the antenna array.

\section{IV.PARAMETRIC Study Design}

In order to address the effects of the design parameters, multiple parametrical studies are carried out using CSTMWS simulator. Fig. 5 shows some of the parametric studies for slots length $\left(S_{L}\right)$, slots width $\left(S_{w}\right)$, foam substrate height (Hight) and outer radius of the upper rings $\left(R_{\text {out }}\right)$. It can be concluded that, increasing in slots width, slots length or outer radius of the upper rings tend to decreasing the resonance frequency, while increasing the foam substrate height tends to increase the resonance frequency location. 


\section{$2021,38^{\text {th }}$ NATIONAL RADIO SCIENCE CONFERENCE \\ (NRSC 2021), July 27-29, 2021}

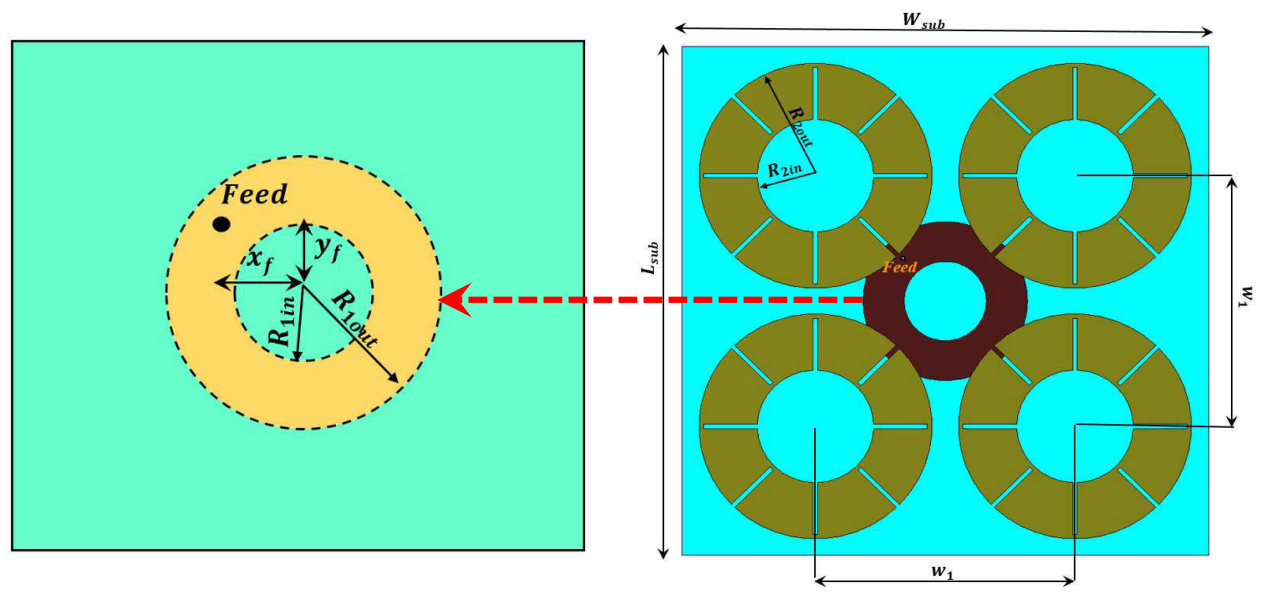

(a)

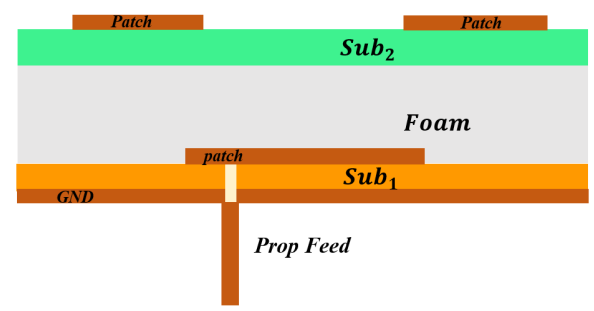

(b)

Fig. 4: (a) The top view of the upper layer with meander slots annular rings, and (b) the side view of the proposed structure.

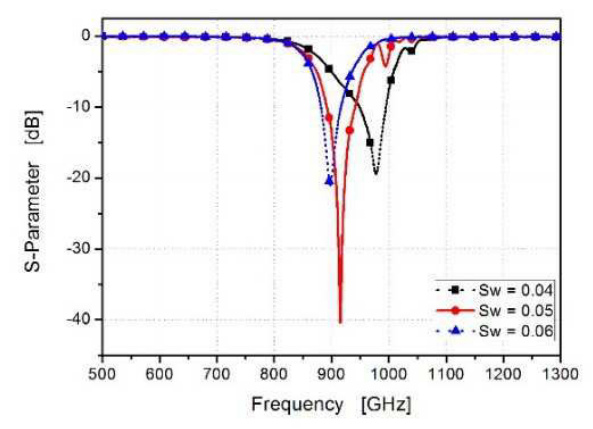

(a)

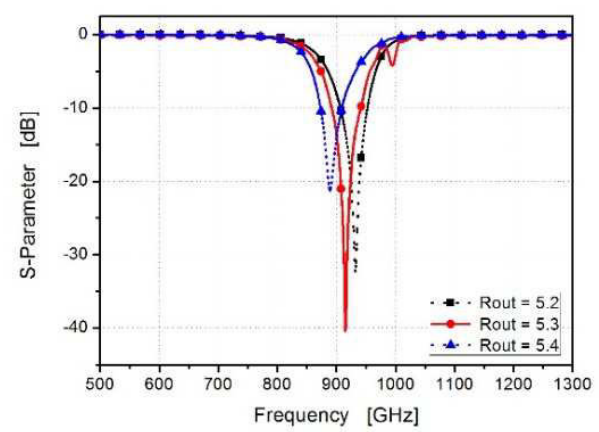

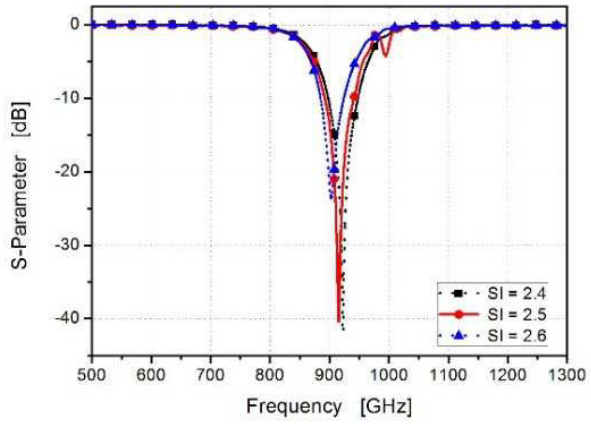

(b)

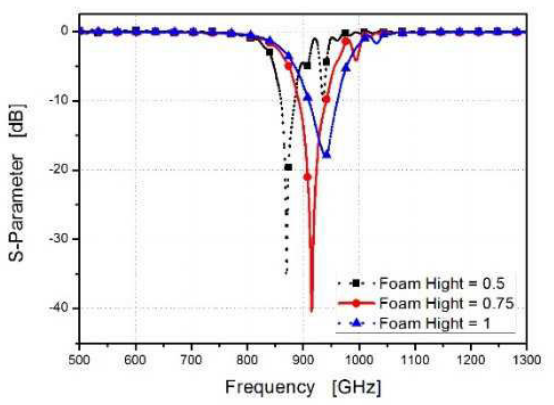

Fig. 5: The effect of (a) the slots width, (b) the slots length, (c) the outer radius of the patch antenna, and (d) the foam substrate (c) height on the reflection coefficient $\left(\mathrm{S}_{11}\right)$. 


\section{1, 38 th NATIONAL RADIO SCIENCE CONFERENCE \\ (NRSC 2021), July 27-29, 2021}

Mansoura University, Mansoura, Egypt

\section{RESUlts AND DiscuSsions}

The proposed antenna is constructed to operate as RFID reader in the UHF band at a resonance frequency of $915 \mathrm{MHz}$. The antenna structure is designed, simulated, and optimized using a commercial electromagnetic simulation (CSTMWS). The antenna results are verified by the results of HFSS software. Fig. 6 shows the return loss $\left(\mathrm{S}_{11}\right)$ results of the proposed structure for both CSTMWS and HFSS simulators. Maximum return loss obtained at the central frequency is $-40.44 \mathrm{~dB}(-30.3 \mathrm{~dB}$ in HFSS simulator). The bandwidth of the designed antenna for $-10 \mathrm{~dB}$ bandwidth is $49.25 \mathrm{MHz}$, as it extends from $892 \mathrm{MHz}$ to $941.25 \mathrm{MHz}(50.75 \mathrm{MHz}$ from $891.5 \mathrm{MHz}$ to $942.25 \mathrm{MHz}$ in HFSS), achieving around $5.38 \%$ bandwidth compared with $8 \mathrm{MHz}$ bandwidth for a single element antenna. The radiation pattern of the proposed structure is simulated in CSTMWS and compared with HFSS results. The antenna achieves a high gain of $12.5 \mathrm{dBi}$ at a designed frequency with increasing in the gain by $2.63 \mathrm{dBi}$ compared with the gain for a single element antenna. The E-plane and H-plane radiation patterns are obtained as shown in Fig. 7.

Fig. 8 shows the overall gain verses frequency for both CSTMWS and HFSS simulators. In Fig. 9, the 3D radiation pattern of the proposed structure at a resonance frequency $(915 \mathrm{MHz})$ is presented. The overall antenna gain versus frequency is also calculated. Fig. 10 shows the current distribution for the proposed structure. A comparison between the proposed work and others work is presented in Table 2. It can be noticed that, our design shows much higher gain compared with others designs, which gives it a superior performance in RFID tag reading /writing.

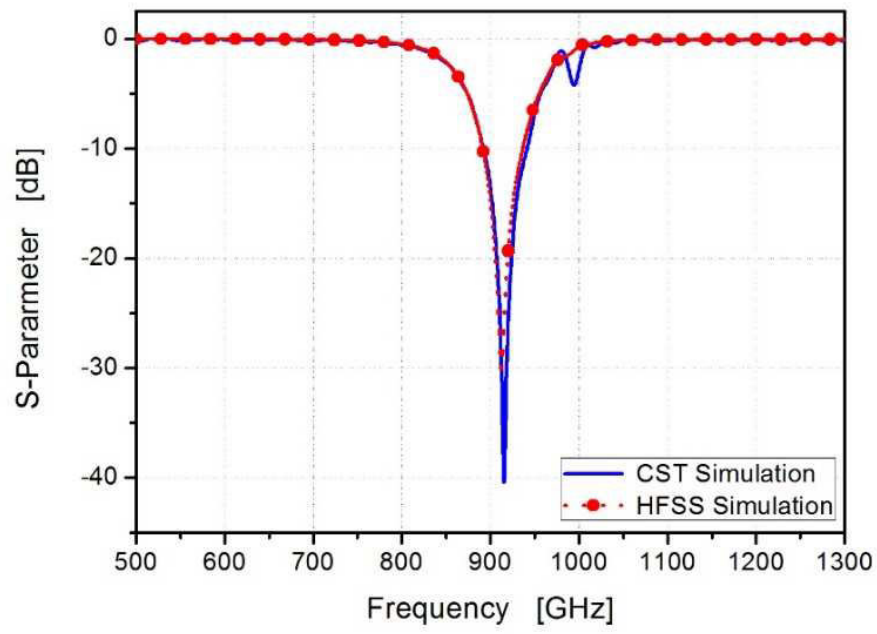

Fig. 6: The return loss results of the proposed structure for both CSTMWS and HFSS simulators.

Table 2: A comparison between the proposed structure and previous reported designs.

\begin{tabular}{|c|c|c|c|c|c|}
\hline Ref. & $\begin{array}{c}\text { Resonance } \\
\text { Frequency (MHz) }\end{array}$ & Gain (dBi) & $\mathbf{S}_{\mathbf{1 1}}(\mathbf{d B})$ & $\begin{array}{c}\text { Antenna Size } \\
\left(\mathbf{m m}^{\mathbf{3}}\right)\end{array}$ & $\begin{array}{c}\text { Bandwidth } \\
(\mathbf{M H z})\end{array}$ \\
\hline$[4]$ & 915 & 0.6 & -22 & $60 \times 60 \times 7$ & 26 \\
\hline$[9]$ & 915 & 7 & -37 & $280 \times 280 \times 30$ & 26 \\
\hline$[11]$ & 915 & 5.52 & -40 & $110 \times 110 \times 15$ & 207 \\
\hline$[12]$ & 921 & 11 & -22.18 & $208 \times 208 \times 1.6$ & 8.825 \\
\hline $\begin{array}{c}\text { This } \\
\text { Work }\end{array}$ & $\mathbf{9 1 5}$ & $\mathbf{1 2 . 5}$ & $\mathbf{- 4 0 . 4 4}$ & $\mathbf{2 4 0 \times 2 4 0 \times 1 1 . 5 6}$ & $\mathbf{4 9 . 2 5}$ \\
\hline
\end{tabular}




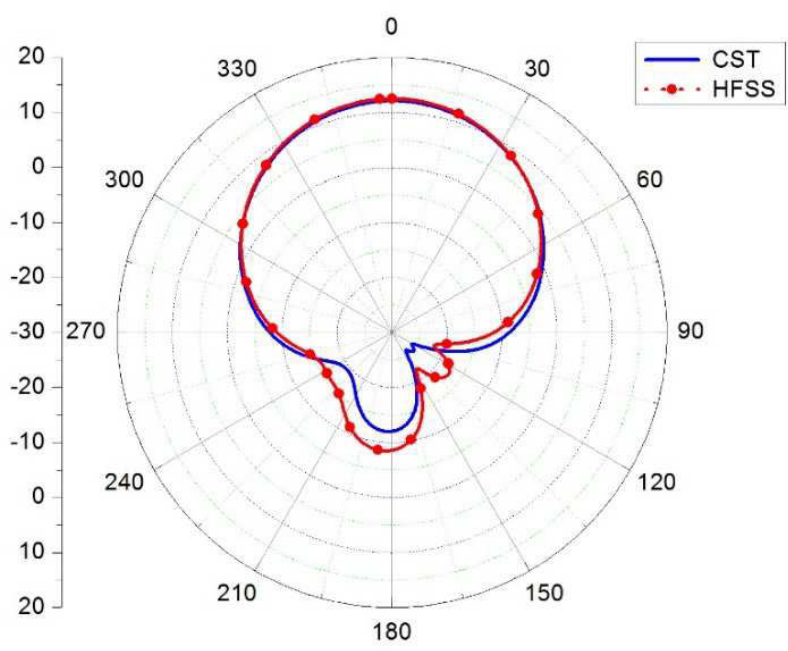

(a)

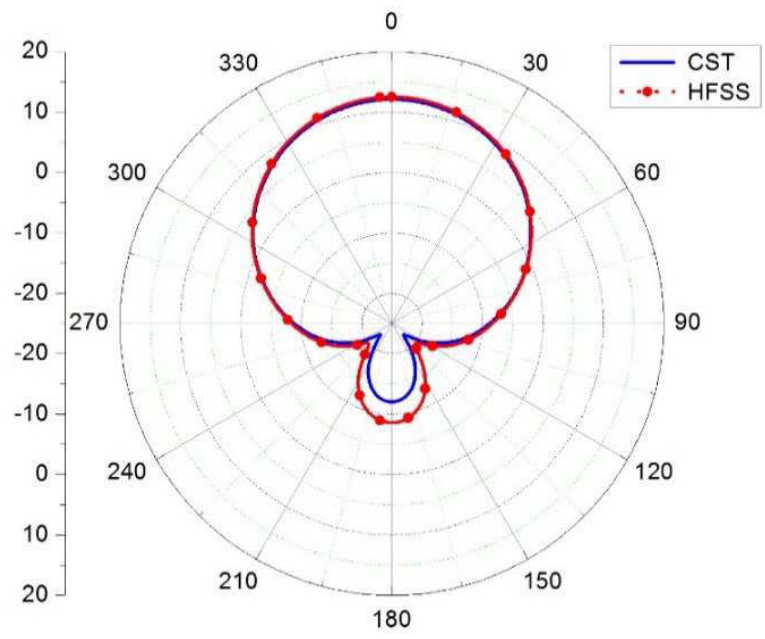

(b)

Fig. 7: The radiation patterns of the proposed antenna, (a) E-plane, and (b) H-plane.

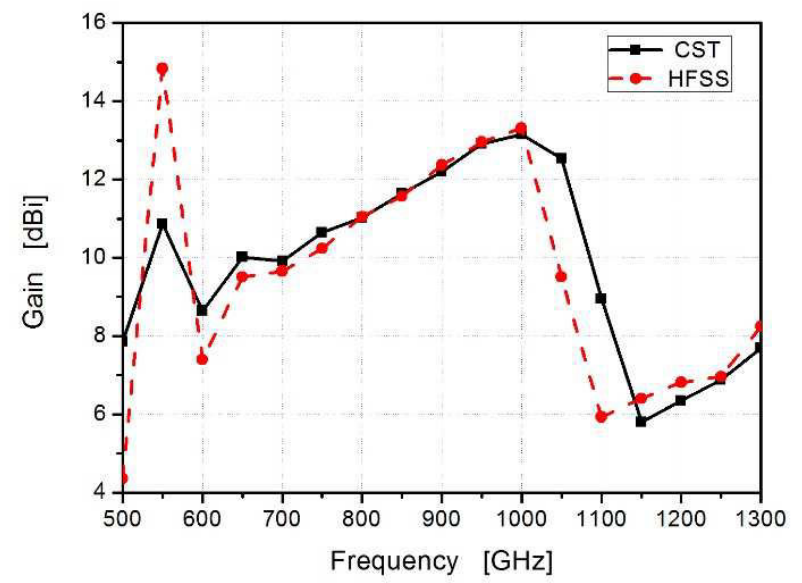

Fig. 8: The overall gain verses frequency for both CSTMWS and HFSS simulators. 


\section{$2021,3^{\text {th }}$ NATIONAL RADIO SCIENCE CONFERENCE \\ (NRSC 2021), July 27-29, 2021}

\section{Mansoura University, Mansoura, Egypt}

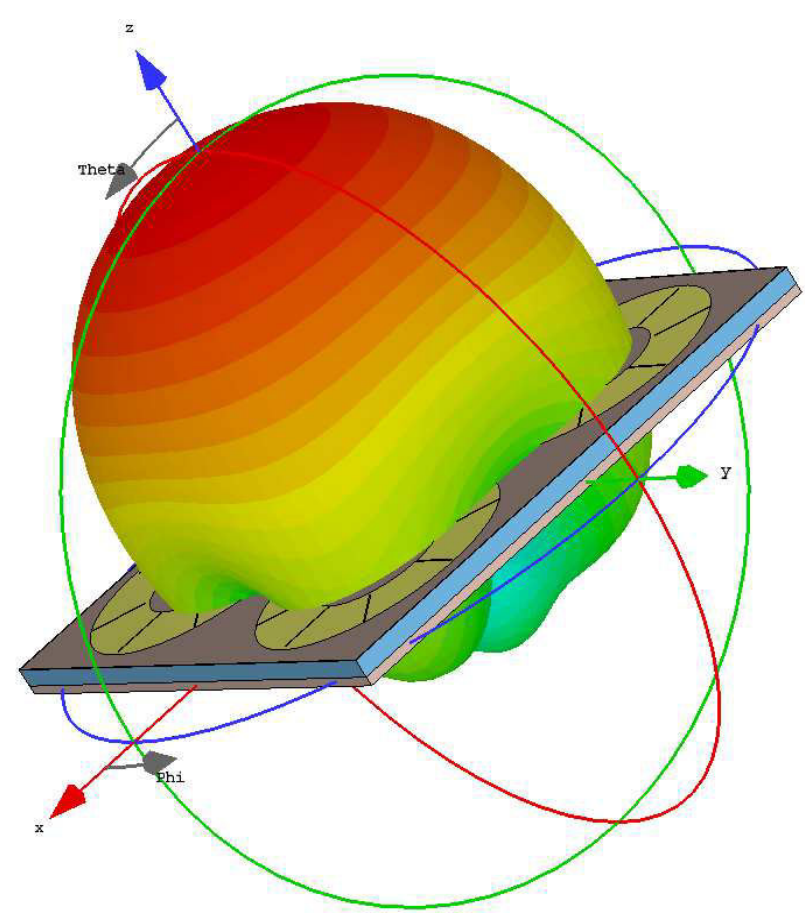

Fig. 9: 3D radiation pattern of the proposed structure at a resonance frequency $(915 \mathrm{MHz})$.

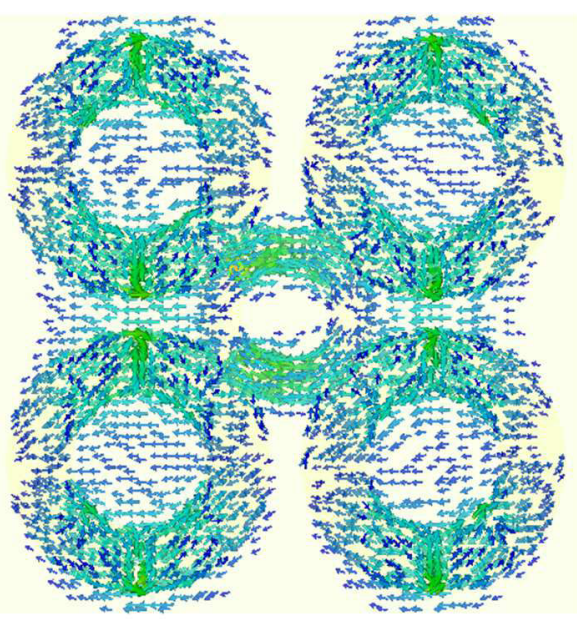

Fig. 10: The current distribution of the proposed structure.

\section{CONCLUSION}

A high-gain, annular ring stacked antenna array with meander slots is introduced for UHF-RFID applications. The design achieves wide bandwidth of 5.38\% around the operating center frequency of $915 \mathrm{MHz}$. Annular ring is used as feeding element for the four-element antenna array through indirect coupling. Two independent software's CSTMWS, HFSS are used to verify the proposed design. The antenna array shows remarkable radiation characteristics and high-gain of more than $12.5 \mathrm{dBi}$ that make this antenna as very good candidate to operate as a reading / writing antenna in any RFID system.

\section{REFERENCES}

[1] Clarke RH, Twede D, Tazelaar JR, Boyer KK, "Radio frequency identification (RFID) performance: The effect of tag orientation and package contents", Packag. Technol. Sci., vol. 19, pp. 45-54, November 2005. 


\section{1, 38 th NATIONAL RADIO SCIENCE CONFERENCE \\ (NRSC 2021), July 27-29, 2021}

Mansoura University, Mansoura, Egypt

[2] Jwo-Shiun Sun, Chia-Hao Wu, “A Broadband circularly polarized antenna of square-ring patch for UHF RFID reader applications," International Journal of Electronics and Communications, vol. 10, pp. 310-312, 2011.

[3] Gerard Zamora Gonzalez,Jordi bonache Albacete,Ferran Marten Antolin "Radio frequency identification (RFID) tags and reader antennas based on conjugate matching and metamaterial concepts", Thesis, Autionoma de Barcelona university, July 2013.

[4] R. Caso, A. Michel, M. Rodriguez-Pino, and P. Nepa, "Dual-band UHF-RFID/WLAN circularly polarized antenna for portable RFID readers," IEEE Transactions On Antennas and Propagation, vol. 62, no. 5, May 2014

[5] Sayan Sarkar, and Bhaskar Gupta, "A dual frequency circularly polarized UHF RFID/WLAN circular patch antenna for RFID readers," IEEE International Conference on RFID Technology and Applications (RFID-TA), Pisa, Italy, Italy, 25-27 Sept. 2019.

[6] Hussein Attia, Allam M. Ameen, Abdel Hamid AM Shaalan, Kamal H. Awadalla, "Multislot multiband monopole antenna for mobile phone applications", IEEE Antennas and Propagation Society International Symposium (APSURSI), Memphis, TN, USA, 6-11 July 2014.

[7] Allam M. Ameen, "Design of a multi-band multi-slot monopole antenna for cellular mobile communications", International Journal of Microwave and Optical Technology, vol. 14, no. 5, pp. 320-326, September 2019.

[8] Allam M. Ameen, Basma M. Yousef, Ahmed M. Attiya, "Mutual coupling reduction between mm-wave microstrip antennas using CSRR metamaterial structure", 37th National Radio Science Conference (NRSC), Cairo, Egypt, 8-10 Sept. 2020.

[9] Ji Yan, Changrong Liu, Xueguan Liu, Jingjing Li, Huiping Guo, and Xinmi Yang, "A Switchable Near-/FarField Reader Antenna for UHF RFID Applications," IEEE Antennas Wireless Propag. Lett., vol. 17, no. 5, pp. 789-793, May 2018.

[10] Jayaram Kizhekke Pakkathillam, Malathi Kanagasabai, and M. Gulam Nabi Alsath, "Compact multiservice UHF RFID reader antenna for near-field and far-field operations", IEEE Antennas Wireless Propag. Lett., vol. 16, no. 5, pp. 147-152, May 2016.

[11] Shiji Wu, Jiade Yuan, Jiangcheng Chen, and Yujie Li, "Compact Circularly Polarized Microstrip Ring Antenna Using Capacitive Coupling Structure for RFID Readers”, IEEE Access, vol. 8, pp. 32617-32623, Feb. 2020.

[12] Syamimi Mohd Norzeli, Ismarani Ismail, Norashidah Md Din, Mohd Tarmizi Ali, Ali Abd Almisreb, and Ammar Ahmed Alkahtani, "A rectangular CSRR based microstrip UHF reader patch antenna for RFID applications”, Indonesian Journal of Electrical Engineering and Computer Science, vol. 17, no. 3, pp. 14341441, March 2020. 